\title{
Two-Dimensional Organic Tin Halide Perovskites with Tunable Visible Emission and Their Use in Light-Emitting Devices
}

\author{
Luis Lanzetta, Jose Manuel Marin-Beloqui, Irene Sanchez-Molina, Dong Ding, and Saif A. Haque*(0)
}

Department of Chemistry and Centre for Plastic Electronics, Imperial College London, South Kensington Campus, London SW7 2AZ, United Kingdom

Supporting Information

ABSTRACT: Hybrid organic lead trihalide perovskites continue to generate significant interest for use in optoelectronic devices such as solar cells and light-emitting devices. However, the toxicity of lead is considered one of the main obstacles to the commercialization of this technology. Although challenging, the replacement of lead by tin is currently the most promising alternative. Herein, we explore a class of low-dimensional, lead-free perovskite materials (2D (PEA) ${ }_{2} \mathrm{SnI}_{x} \mathrm{Br}_{4-x}$, where PEA $\equiv$ $\mathrm{C}_{6} \mathrm{H}_{5} \mathrm{CH}_{2} \mathrm{CH}_{2} \mathrm{NH}_{3}^{+}$) with tunable optical properties in the visible region of the spectrum. Specifically, we show that $2 \mathrm{D}(\mathrm{PEA})_{2} \mathrm{SnI}_{4}$ perovskite exhibits superior photoluminescence properties to conventional 3D $\mathrm{CH}_{3} \mathrm{NH}_{3} \mathrm{SnI}_{3}$ and that $(\mathrm{PEA})_{2} \mathrm{SnI}_{4}$ can act as a sensitizer on mesoporous $\mathrm{TiO}_{2}$. We go on to demonstrate visible $(\sim 630 \mathrm{~nm})$ electroluminescence from a device employing a (PEA) $)_{2} \mathrm{SnI}_{4}$ emitter sandwiched between ITO/PEDOT:PSS

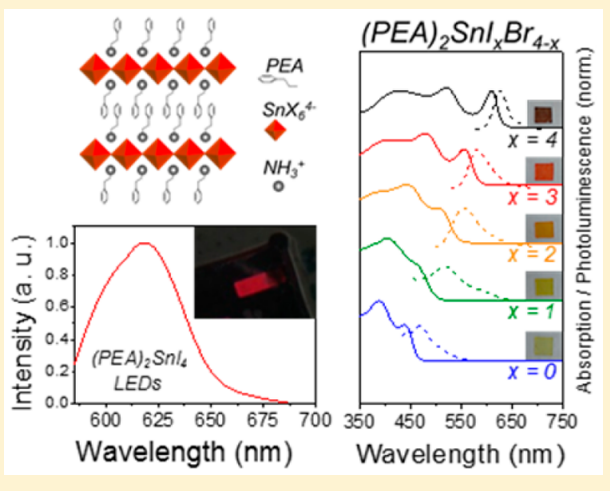
and $\mathrm{F8} / \mathrm{LiF} / \mathrm{Al}$ as hole and electron injection electrodes, respectively. These devices reach a luminance of $0.15 \mathrm{~cd} / \mathrm{m}^{2}$ at 4.7 $\mathrm{mA} / \mathrm{cm}^{2}$ and an efficacy of $0.029 \mathrm{~cd} / \mathrm{A}$ at $3.6 \mathrm{~V}$. This proof-of-principle device indicates a viable path to low-dimensional, lead-free perovskite optoelectronics.

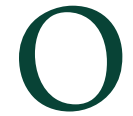

rganic lead halide perovskites have been reported as an outstanding class of semiconducting materials for optoelectronic applications, with numerous examples in the specific fields of solar cells ${ }^{1-5}$ and light-emitting diodes (LEDs). ${ }^{6-9}$ The main advantages that make this family of materials attractive for such applications are their low-cost preparation via solution processing, good charge transport properties, and structural flexibility for optical band gap tuning. ${ }^{10,11}$ However, the relatively low stability of perovskite materials ${ }^{12}$ and the high toxicity of lead remain problems. Leadfree perovskite alternatives based on tin (e.g., 3D $\mathrm{CH}_{3} \mathrm{NH}_{3} \mathrm{SnI}_{3}$ ) have already been investigated as both absorbers $^{13-15}$ and light emitters ${ }^{16,17}$ in optoelectronic devices with promising results. However, the replacement of $\mathrm{Pb}^{2+}$ by $\mathrm{Sn}^{2+}$ worsens the stability of the perovskite material as tin in its $2+$ oxidation state is prone to undergo oxidation in ambient conditions. More specifically, degradation of $\mathrm{CH}_{3} \mathrm{NH}_{3} \mathrm{SnI}_{3}$ perovskites is known to introduce p-type self-doping in the material due to the spontaneous formation of $\mathrm{Sn}^{4+}$ species $/ \mathrm{Sn}^{2+}$ vacancies in the structure, which makes the perovskite material exhibit metal-like behavior. ${ }^{18-21}$ Unfortunately, the high intrinsic conductivity of tin-based hybrid perovskites usually compromises device performance, reproducibility, and stability due to the unwanted carrier recombination and current leakage. ${ }^{21}$ At present, the most commonly used method to partially overcome this issue involves the addition of tin(II) halides in perovskite film processing solutions to act as vacancy modulators. $^{15,21,22}$ However, self-doping in tin-based perovskites remains an issue to the realization of lead-free optoelectronic devices. As such, the design and synthesis of Sn-based perovskite materials with preferable innate semiconducting properties and improved stability is needed.

Interestingly, Mitzi et al. have demonstrated that the metallic conductivity of conventional $3 \mathrm{D}$ organic tin halide perovskites can be suppressed by progressively reducing the crystal dimensionality, causing a metal-to-semiconductor shift when increasing the $2 \mathrm{D}$ or layered character of the perovskite structure. $^{23}$ Therefore, this class of $2 \mathrm{D}$ hybrid tin-based perovskites represents a pathway to overcome the aforementioned intrinsic limitations of their $3 \mathrm{D}$ counterparts. In addition to the undesired metallic behavior of conventional $3 \mathrm{D}$ $\mathrm{CH}_{3} \mathrm{NH}_{3} \mathrm{SnI}_{3}$ perovskites, the ability to tune the emission properties in such $3 \mathrm{D}$ tin-based materials into the visible (e.g., red, green, and blue) also remains a challenge, with reports based only on NIR emitters. ${ }^{16,17}$ Herein, we demonstrate

Received: May 15, 2017

Accepted: June 20, 2017

Published: June 27, 2017 

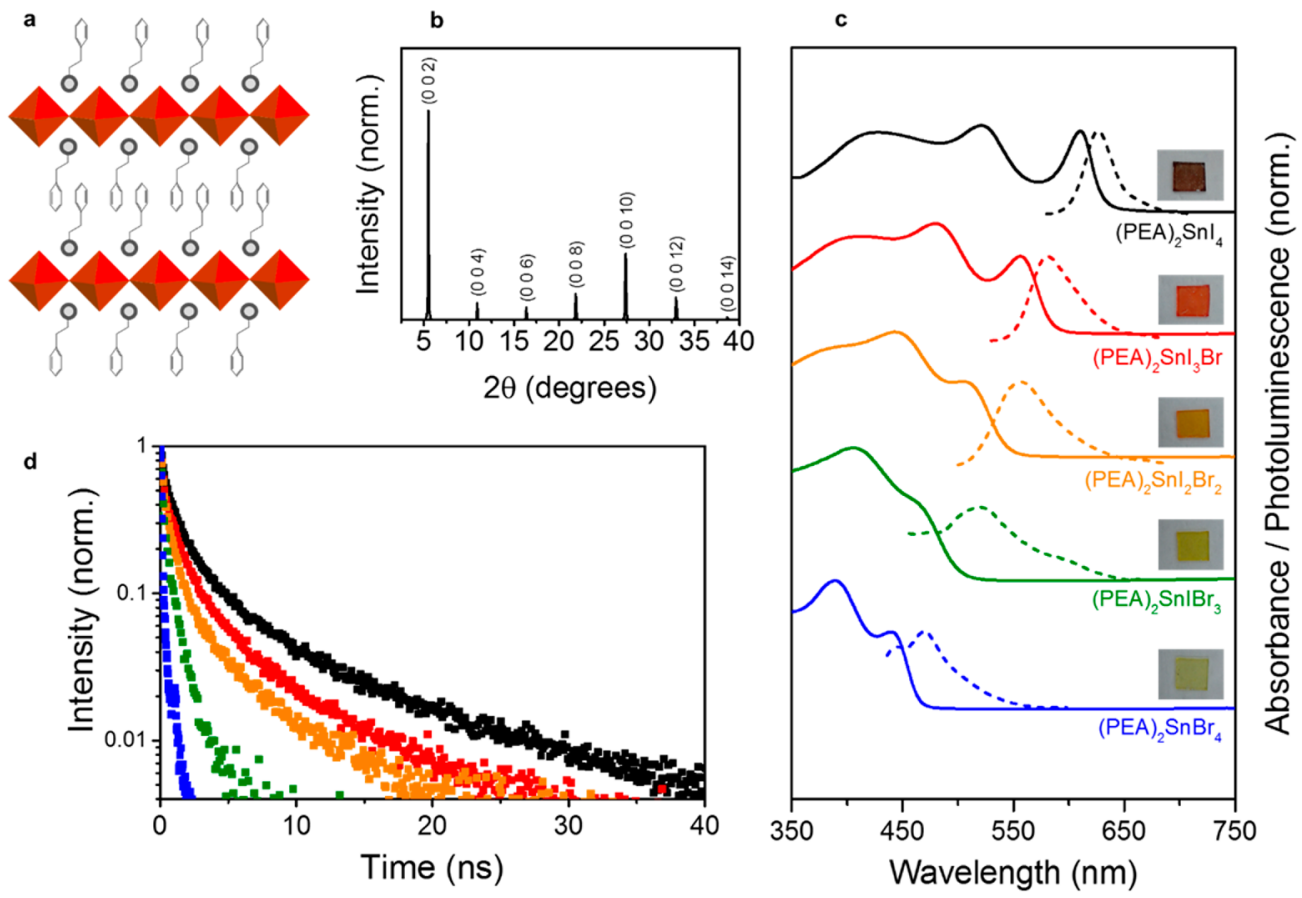

Figure 1. (a) General crystal schematic of a (PEA) ${ }_{2} \mathrm{SnI}_{x} \mathrm{Br}_{4-x}$ perovskite (light gray balls: $-\mathrm{NH}_{3}{ }^{+}$groups; red polyhedra: corner-sharing $\mathrm{SnX}_{6}^{4-}$ octahedra, where $\mathrm{X}$ represents a halide) with alternating organic-inorganic layers. (b) P-XRD pattern of a (PEA) ${ }_{2} \mathrm{SnI}_{4}$ thin film processed on glass. Peaks were assigned to crystal planes by using literature references. ${ }^{24}$ (c) Normalized absorbance (solid lines) and PL (dashed lines) spectra of (PEA) $)_{2} \mathrm{SnI}_{4}$ (black lines), (PEA) ${ }_{2} \mathrm{SnI}_{3} \mathrm{Br}$ (red lines), (PEA) $\mathrm{SnI}_{2} \mathrm{Br}_{2}$ (orange lines), (PEA) $\mathrm{SnIBr}_{3}$ (green lines), and (PEA) ${ }_{2} \mathrm{SnBr}_{4}$ (blue lines) perovskite thin films processed on glass (photographs of samples shown for each $x$ value). (d) Time-resolved PL of $(\mathrm{PEA})_{2} \mathrm{SnI}_{4}$ (black squares; probe: $\left.635 \mathrm{~nm}\right),(\mathrm{PEA})_{2} \mathrm{SnI}_{3} \mathrm{Br}$ (red squares; probe: $580 \mathrm{~nm}$ ), $(\mathrm{PEA})_{2} \mathrm{SnI}_{2} \mathrm{Br}_{2}$ (orange squares; probe: $556 \mathrm{~nm}$ ), $(\mathrm{PEA})_{2} \mathrm{SnIBr}_{3}$ (green squares; probe: $522 \mathrm{~nm}$ ), and $(\mathrm{PEA})_{2} \mathrm{SnBr}_{4}$ (blue squares; probe: $468 \mathrm{~nm}$ ) obtained with $404 \mathrm{~nm}$ excitation.

tunable visible emission properties (e.g., $\sim 640$ to $\sim 450 \mathrm{~nm}$ ) in $2 \mathrm{D}(\mathrm{PEA})_{2} \mathrm{SnI}_{x} \mathrm{Br}_{4-x}$ by varying the $\mathrm{I} / \mathrm{Br}$ ratio.

Despite the preferable properties shown by layered 2D tinbased materials, their incorporation in optoelectronic and electronic devices remains largely unexplored, with only a few examples in the literature based on field-effect transistors. ${ }^{24-26}$ While the lead-containing version of reduced-dimensionality perovskites $^{27-29}$ has been recently used in the fabrication of solar cells with enhanced ambient stability,,$^{27,30-32}$ as well as in light-emitting devices, ${ }^{33-40}$ tin-based materials are yet to be exploited in photovoltaic and LED applications. In this study, we present the preparation and optical characterization of tunable $2 \mathrm{D}(\mathrm{PEA})_{2} \mathrm{SnI}_{x} \mathrm{Br}_{4-x}\left(\mathrm{PEA} \equiv \mathrm{C}_{6} \mathrm{H}_{5} \mathrm{CH}_{2} \mathrm{CH}_{2} \mathrm{NH}_{3}{ }^{+} ; x=\right.$ $0-4)$ perovskite thin films. More specifically, we demonstrate that (i) $2 \mathrm{D}(\mathrm{PEA})_{2} \mathrm{SnI}_{4}$ exhibits superior photoluminescence (PL) properties relative to $\mathrm{CH}_{3} \mathrm{NH}_{3} \mathrm{SnI}_{3}$ and (ii) 2D (PEA) $)_{2} \mathrm{SnI}_{4}$ perovskites can function as a light-harvesting agent and sensitizer on mesoporous $\mathrm{TiO}_{2}$. Moreover, to demonstrate that reduced dimensionality $2 \mathrm{D}(\mathrm{PEA})_{2} \mathrm{SnI}_{x} \mathrm{Br}_{4-x}$ perovskites can be used in optoelectronic devices, we report LEDs based on (PEA) $)_{2} \mathrm{SnI}_{4}$ emitter layers.

$2 \mathrm{D}(\mathrm{PEA})_{2} \mathrm{SnI}_{x} \mathrm{Br}_{4-x}$ perovskites were prepared as described in the experimental section (see the Supporting Information). In order to achieve a full $2 \mathrm{D}$ structure, the methylammonium cation in the $\mathrm{CH}_{3} \mathrm{NH}_{3} \mathrm{SnI}_{x} \mathrm{Br}_{3-x}$ perovskite formula was replaced by a phenylethylammonium (PEA) cation with the purpose of introducing steric hindrance during crystallization. This is known to drive a self-assembly crystallization process in which an alternating stack of organic-inorganic layers is obtained (Figure 1a). It has been previously shown that semiconducting character of the inorganic layers in the $2 \mathrm{D}$ material provides smaller energy level gaps that act as charge carrier radiative recombination sites by concentrating electrons and holes in these regions and strengthening their mutual interaction (increase in exciton binding energy ${ }^{41,42}$ ). Powder Xray diffraction $(\mathrm{P}-\mathrm{XRD})$ patterns of $(\mathrm{PEA})_{2} \mathrm{SnI}_{4}$ perovskite thin films (Figure $1 \mathrm{~b}$ ) confirm the high crystallinity of our samples. The presence of only (001) reflections in the XRD spectrum suggests parallel orientation of the perovskite planes with respect to the substrate, as previously reported for this family of materials. ${ }^{24,43}$ P-XRD data of all of the synthesized (PEA) ${ }_{2} \mathrm{SnI}_{x} \mathrm{Br}_{4-x}$ perovskites (Figure $\mathrm{S} 1$ ) confirms the presence of isostructural crystal lattices in this family of tunable materials. We note that no peaks corresponding to $\mathrm{SnI}_{2}, \mathrm{SnBr}_{2}, \mathrm{PEAI}$, or $\mathrm{PEABr}$ were detected in the X-ray diffraction patterns, thus confirming complete reaction between both precursors. From the (002) reflections, we estimate separations ( $d$ spacing) between inorganic layers of $d=16.06$ (for $x=4$ ) and 16.34 (for $x=3,2,1,0) \AA$, indicating that $\mathrm{Br}$ replacement slightly increases the distance between the perovskite sheets.

In Figure 1c, we present the UV-vis absorption and PL properties of (PEA) $)_{2} \mathrm{SnI}_{x} \mathrm{Br}_{4-x}$. It can be seen that optical absorption and emission spectra of perovskite (PEA) $)_{2} \mathrm{SnI}_{x} \mathrm{Br}_{4-x}$ films become more blue-shifted with increasing bromide content. The optical band gaps of (PEA) ${ }_{2} \mathrm{SnI}_{x} \mathrm{Br}_{4-x}$ films were estimated to be $\sim 1.97, \sim 2.13, \sim 2.28, \sim 2.47$, and $\sim 2.66$ $\mathrm{eV}$ for samples with $x=4,3,2,1$, and 0 , respectively. In the absorbance spectra (solid lines), sharp absorption bands can be observed, which are attributed to the excitonic behavior of these materials. We note that the optical band gap of perovskites becomes larger when reducing the dimensionality of the material from $3 \mathrm{D} \mathrm{CH}_{3} \mathrm{NH}_{3} \mathrm{SnI}_{3}$ to $2 \mathrm{D}(\mathrm{PEA})_{2} \mathrm{SnI}_{4}(1.26$ 
vs $1.97 \mathrm{eV}$, respectively; see Figure S2). We attribute this to a quantum size effect, as reported elsewhere for similar perovskite materials. ${ }^{27,44}$ On the other hand, the PL spectra of $(\mathrm{PEA})_{2} \mathrm{SnI}_{x} \mathrm{Br}_{4-x}$ (dashed lines) exhibit peaks at $627(x=4)$, $580(x=3), 556(x=2), 522(x=1)$, and $468(x=0) \mathrm{nm}$. The variation in the steady-state $\mathrm{PL}$ peak wavelengths of our perovskites is linear with respect to the $x$ value in (PEA) ${ }_{2} \mathrm{SnI}_{x} \mathrm{Br}_{4-x}$, which is consistent with Vegard's law (Figure S3). We note that the small Stokes shift observed in these 2D perovskites $(x=4: 16 \mathrm{~nm} ; x=3: 24 \mathrm{~nm} ; x=2: 52 \mathrm{~nm} ; x=1$ : $55 \mathrm{~nm} ; x=0: 29 \mathrm{~nm}$ ) suggests minimal vibronic lattice relaxation after photon absorption, as expected from a reduced dimensionality crystalline material. Red-shifted emission tails in mixed-halide (PEA) ${ }_{2} \mathrm{SnI}_{x} \mathrm{Br}_{4-x}$ PL spectra become more prominent with higher bromide content in perovskites, which may be related to defect luminescence in the perovskites with increased $\mathrm{Br}$ content. Time-resolved PL decays of (PEA) ${ }_{2} \mathrm{SnI}_{x} \mathrm{Br}_{4-x}$ are shown in Figure $1 \mathrm{~d}$. It is pertinent to note that an increase in $\mathrm{Br}$ leads to shorter decay lifetimes $(x=$ 4: $\tau_{1}=8.85 \pm 0.18 \mathrm{~ns} ; x=3: \tau_{1}=5.99 \pm 0.18 \mathrm{~ns} ; x=2: \tau_{1}=$ $5.52 \pm 0.21 \mathrm{~ns} ; x=1: \tau_{1}=5.24 \pm 1.57 \mathrm{~ns} ; x=0: \tau_{1}=1.84 \pm$ $0.69 \mathrm{~ns}$; see Table S1 for fitting details). This observation is consistent with $\mathrm{Br}$-rich perovskites exhibiting higher lattice disorder, ${ }^{17}$ causing crystal defects that act as trap states and give rise to shorter-lived PL. This assertion is supported by PL quantum efficiency (PLQE) values presented in Table 1. These data show that increasing the $\mathrm{Br}$ content in the mixed iodidebromide perovskites (e.g., (PEA) ${ }_{2} \mathrm{SnI}_{x} \mathrm{Br}_{4-x}$ where $x=3-1$ ) leads to a reduction in PLQE values.

Table 1. PLQE Values for (PEA) $)_{2} \mathrm{SnI}_{4},(\mathrm{PEA})_{2} \mathrm{SnI}_{3} \mathrm{Br}$, $(\mathrm{PEA})_{2} \mathrm{SnI}_{2} \mathrm{Br}_{2},(\mathrm{PEA})_{2} \mathrm{SnIBr}_{3},(\mathrm{PEA})_{2} \mathrm{SnBr}_{4}$, and $\mathrm{CH}_{3} \mathrm{NH}_{3} \mathrm{SnI}_{3}$ Thin Films Processed on Glass

\begin{tabular}{lc}
\multicolumn{1}{c}{ sample } & PLQE (\%) \\
$\mathrm{CH}_{3} \mathrm{NH}_{3} \mathrm{SnI}_{3}$ & 0.01 \\
$(\mathrm{PEA})_{2} \mathrm{SnI}_{4}$ & 0.24 \\
$(\mathrm{PEA})_{2} \mathrm{SnI}_{3} \mathrm{Br}$ & 0.13 \\
$(\mathrm{PEA})_{2} \mathrm{SnI}_{2} \mathrm{Br}_{2}$ & 0.12 \\
$(\mathrm{PEA})_{2} \mathrm{SnIBr}_{3}$ & 0.02 \\
$(\mathrm{PEA})_{2} \mathrm{SnBr}_{4}$ & 0.04
\end{tabular}

We next consider the photophysical properties of tin-based $2 \mathrm{D}$ perovskites relative to conventionally used $3 \mathrm{D}$ hybrid organic tin halide perovskite materials (Figure 2a). For this purpose, we compared the PL properties of $2 \mathrm{D}(\mathrm{PEA})_{2} \mathrm{SnI}_{4}$ and the prototypical compound, namely, $3 \mathrm{D} \mathrm{CH}_{3} \mathrm{NH}_{3} \mathrm{SnI}_{3}$. Timeresolved PL decays were collected by measuring the emission at $\sim 900 \mathrm{~nm}$ for $\mathrm{CH}_{3} \mathrm{NH}_{3} \mathrm{SnI}_{3}$ and $635 \mathrm{~nm}$ for (PEA) ${ }_{2} \mathrm{SnI}_{4}$ following excitation at $404 \mathrm{~nm}$. The corresponding steadystate PL spectra normalized to sample absorption (Figure S4) are shown in Figure 2a (inset). From the data presented in Figure 2a (inset), it can be seen that $\mathrm{CH}_{3} \mathrm{NH}_{3} \mathrm{SnI}_{3}$ exhibits a relatively weak emission band centered at $\sim 950 \mathrm{~nm}$ (blue curve); this observation is in agreement with previous work. ${ }^{10}$ In contrast, $(\mathrm{PEA})_{2} \mathrm{SnI}_{4}$ displays a more intense $(\sim 7.5$ times $)$ and blue-shifted emission (red curve) relative to $\mathrm{CH}_{3} \mathrm{NH}_{3} \mathrm{SnI}_{3}$. As can be seen in Figure 2a, (PEA) $)_{2} \mathrm{SnI}_{4}$ thin films show PL dynamics with a noticeably longer decay time relative to $\mathrm{CH}_{3} \mathrm{NH}_{3} \mathrm{SnI}_{3}$ (dominant time constant $\tau_{1}: 8.851 \pm 0.176$ vs $0.109 \pm 0.005 \mathrm{~ns}$, respectively; see Table S1). Decay times obtained for $3 \mathrm{D} \mathrm{CH}_{3} \mathrm{NH}_{3} \mathrm{SnI}_{3}$ perovskite are comparable to those previously reported in the literature. ${ }^{16}$ Our observation of a longer time constant $\tau_{1}$ in $(\mathrm{PEA})_{2} \mathrm{SnI}_{4}$ relative to $\mathrm{CH}_{3} \mathrm{NH}_{3} \mathrm{SnI}_{3}$ is consistent with a higher PLQE in the 2D material. This is in agreement with the directly measured PLQE values ((PEA) $)_{2} \mathrm{SnI}_{4}: 0.24 \% ; \mathrm{CH}_{3} \mathrm{NH}_{3} \mathrm{SnI}_{3}: 0.01 \%$; Table 1$)$. The better PLQE of (PEA) $)_{2} \mathrm{SnI}_{4}$ as compared to that of $\mathrm{CH}_{3} \mathrm{NH}_{3} \mathrm{SnI}_{3}$ is consistent with the aforementioned excitonic character of $(\mathrm{PEA})_{2} \mathrm{SnI}_{4}$. The $2 \mathrm{D}$ structure of this material provides greater spatial confinement of electrons and holes, which in turn leads to a stronger Coulomb interaction between them than that occurring in its 3D counterpart, thus increasing the likelihood of radiative recombination.

Next, we investigated whether (PEA) ${ }_{2} \mathrm{SnI}_{4}$ can act as a sensitizer on mesoporous (mp) $\mathrm{TiO}_{2}$. To this end, the (PEA) ${ }_{2} \mathrm{SnI}_{4}$ perovskite was deposited onto $\mathrm{mp}-\mathrm{TiO}_{2}$ layers to form $\mathrm{mp}-\mathrm{TiO}_{2} /(\mathrm{PEA})_{2} \mathrm{SnI}_{4}$ heterojunctions, as described in the methods section (Supporting Information); in this architecture, $\mathrm{TiO}_{2}$ functions as the electron acceptor and (PEA) $)_{2} \mathrm{SnI}_{4}$ as the electron donor. First, PL quenching was used to study photoinduced charge separation in $\mathrm{mp}-\mathrm{TiO}_{2} /(\mathrm{PEA})_{2} \mathrm{SnI}_{4}$ films. Figure 2a (inset) presents the steady-state PL for $\mathrm{mp}$ $\mathrm{TiO}_{2} /(\mathrm{PEA})_{2} \mathrm{SnI}_{4}$ (red curve) and pristine (PEA) $)_{2} \mathrm{SnI}_{4}$ films (black curve) following excitation of the perovskite at $500 \mathrm{~nm}$ (spectra normalized to sample absorption at $500 \mathrm{~nm}$; Figure S3). By evaluation of the peak heights, we observe a 4-fold decrease in the (PEA) $)_{2} \mathrm{SnI}_{4} \mathrm{PL}$ signal when depositing the material onto mp- $\mathrm{TiO}_{2}$. PL quenching in $(\mathrm{PEA})_{2} \mathrm{SnI}_{4} / \mathrm{mp}-\mathrm{TiO}_{2}$ films was further investigated using time-resolved $\mathrm{PL}$ spectroscopy (Figure $2 \mathrm{a}$ ). We note that the dominant lifetime $\tau_{1}$ is shorter for $\mathrm{mp}-\mathrm{TiO}_{2} /(\mathrm{PEA})_{2} \mathrm{SnI}_{4}$ (black squares) than that for the control (PEA) $)_{2} \mathrm{SnI}_{4}$ sample (red squares) $(1.529 \pm 0.644$ vs $8.851 \pm 0.176 \mathrm{~ns}$, respectively; see Table S1). This observation is consistent with fewer carriers recombining radiatively in the $\mathrm{mp}-\mathrm{TiO}_{2} /$ perovskite sample.

Next, we turned to microsecond transient absorption spectroscopy ( $\mu$ s-TAS) to obtain direct evidence for the presence of charge separation in $\mathrm{mp}-\mathrm{TiO}_{2} /(\mathrm{PEA})_{2} \mathrm{SnI}_{4}$ films (Figure 2b). Pulsed optical excitation $\left(567 \mathrm{~nm}, 7 \mu \mathrm{J} \cdot \mathrm{cm}^{-2}, 4\right.$ $\mathrm{Hz})$ of $\mathrm{mp}-\mathrm{TiO}_{2} /(\mathrm{PEA})_{2} \mathrm{SnI}_{4}$ resulted in the appearance of a broad transient absorption feature in the near-infrared region (Figure $2 \mathrm{~b}$, inset black circles), which we mainly attribute to oxidized (PEA) $)_{2} \mathrm{SnI}_{4}$, although a small contribution of electrons in $\mathrm{TiO}_{2}$ cannot be excluded. The dynamics of the charge recombination reaction between electrons in the $\mathrm{TiO}_{2}$ and photo-oxidized (PEA) ${ }_{2} \mathrm{SnI}_{4}$ were determined by monitoring the decay of the transient absorption band at $1600 \mathrm{~nm}$. Typical kinetic traces (Figure 2b; black curve) display multiexponential behavior on micro- to millisecond time scales similar to those generally observed in $\mathrm{TiO}_{2} /$ dye systems. We note that the absence of growth in the $\triangle \mathrm{OD}$ signal on early time scales in the $\mathrm{mp}-\mathrm{TiO}_{2} /(\mathrm{PEA})_{2} \mathrm{SnI}_{4}$ sample indicates that the primary charge separation reaction (Figure $2 \mathrm{c}$, left panel) is occurring on time scales faster than the instrument response of our transient spectrometer $(\mathrm{IR} \approx 100 \mathrm{~ns})$. We further note that no transient absorption feature, and therefore charge separation, was observed in control mp- $\mathrm{Al}_{2} \mathrm{O}_{3} /(\mathrm{PEA})_{2} \mathrm{SnI}_{4}$ samples (Figure $2 \mathrm{~b}$; green curve); this observation is consistent with the unfavorable energy level alignment at the mp- $\mathrm{Al}_{2} \mathrm{O}_{3}$ / (PEA) ${ }_{2} \mathrm{SnI}_{4}$ heterojunction, as illustrated in Figure $2 \mathrm{c}$ (right panel). Moreover, it is pertinent to note that in contrast to the mp- $\mathrm{TiO}_{2} /(\mathrm{PEA})_{2} \mathrm{SnI}_{4}$ system no transient absorption features were observed in $\mathrm{mp}-\mathrm{TiO}_{2} / 3 \mathrm{D} \mathrm{CH}_{3} \mathrm{NH}_{3} \mathrm{SnI}_{3}$ films (Figure $2 \mathrm{~b}$, orange trace) in any of the analyzed probe wavelengths in the TAS spectrum (Figure $2 b$, inset orange circles). This 

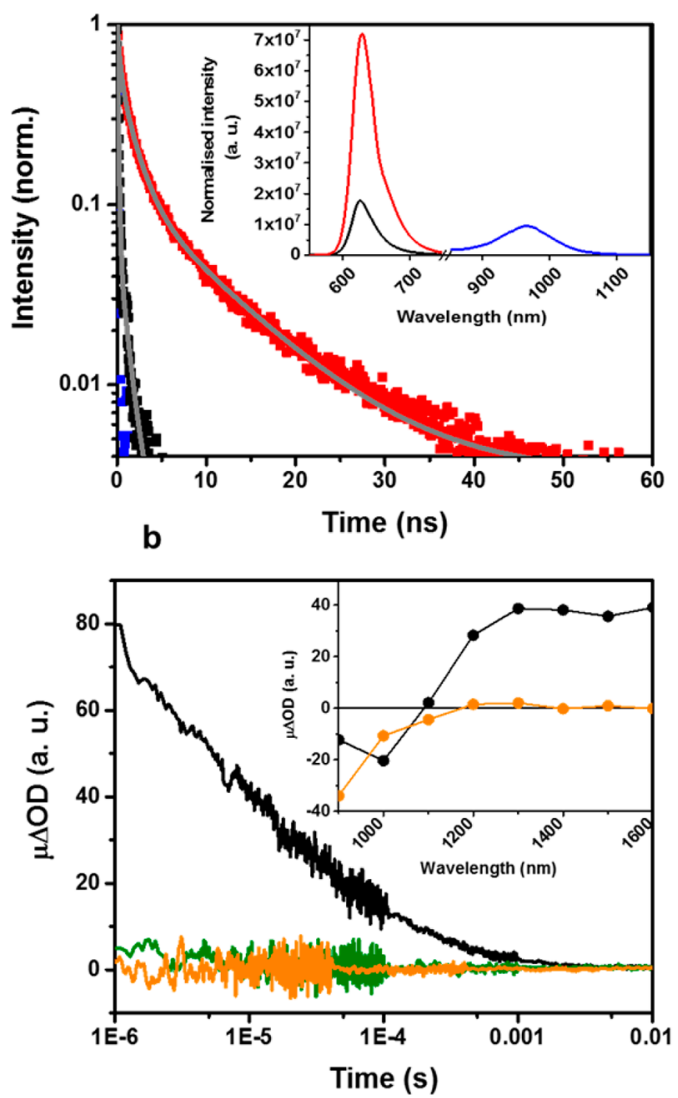

C

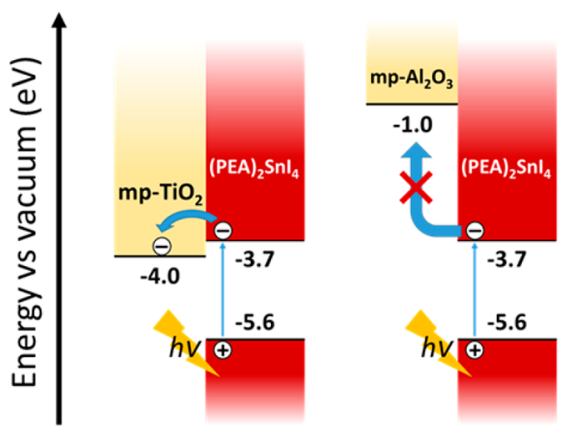

d

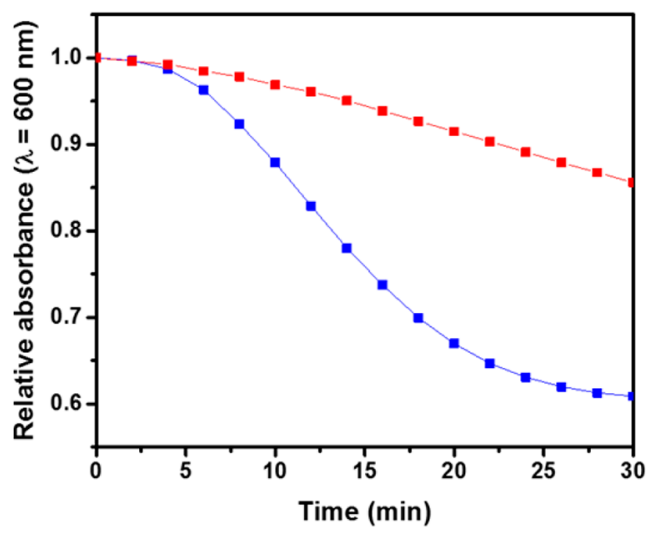

Figure 2. (a) Time-resolved PL corresponding to (PEA) $)_{2} \mathrm{SnI}_{4}$ (red squares; probe: $635 \mathrm{~nm}$; gray line: triexponential fitting), mp-TiO ${ }_{2} /$ (PEA) $\mathrm{SnI}_{4}$ (black squares; probe: $635 \mathrm{~nm}$; gray line: biexponential fitting), and $\mathrm{CH}_{3} \mathrm{NH}_{3} \mathrm{SnI}_{3}$ (blue squares; probe: $900 \mathrm{~nm}$ ) films, obtained with $404 \mathrm{~nm}$ excitation. (Inset) Steady-state $\mathrm{PL}$ spectra of (PEA) $\mathrm{SnI}_{4}$ (red line), $\mathrm{mp}-\mathrm{TiO}_{2} /(\mathrm{PEA})_{2} \mathrm{SnI}_{4}\left(\right.$ black curve), and $\mathrm{CH}_{3} \mathrm{NH}_{3} \mathrm{SnI}_{3}(\mathrm{blue}$ line) registered after $500 \mathrm{~nm}$ excitation (spectra were normalized to the absorption of each sample at $500 \mathrm{~nm}$ ). (b) $\mu$-TAS signals of mp-TiO $/$ (PEA) ${ }_{2} \mathrm{SnI}_{4}$ (black trace; pump: $567 \mathrm{~nm}$ ), mp- $\mathrm{Al}_{2} \mathrm{O}_{3} /(\mathrm{PEA})_{2} \mathrm{SnI}_{4}$ (green trace; pump: $567 \mathrm{~nm}$ ), and mp- $\mathrm{TiO}_{2} / \mathrm{CH}_{3} \mathrm{NH}_{3} \mathrm{SnI}_{3}($ orange trace; pump: $567 \mathrm{~nm}$ ) samples registered at $1600 \mathrm{~nm}$. (Inset) Transient absorption spectra of $\mathrm{mp}-\mathrm{TiO}_{2} /\left(\mathrm{PEA}_{2} \mathrm{SnI}_{4}\left(\mathrm{black}\right.\right.$ circles) and mp-TiO ${ }_{2} /$ $\mathrm{CH}_{3} \mathrm{NH}_{3} \mathrm{SnI}_{3}$ (orange circles) samples. (c) Energy band diagrams showing photoinduced interfacial electron transfer from (PEA) $\mathrm{SnI}_{4}$ to $\mathrm{mp}$ $\mathrm{TiO}_{2}$ (left) and the absence of interfacial electron transfer from (PEA) $\mathrm{SnI}_{4}$ to $\mathrm{mp}-\mathrm{Al}_{2} \mathrm{O}_{3}$ (right). Energy values obtained from literature references. ${ }^{26,45,46}$ (d) Time evolution of relative absorption at $600 \mathrm{~nm}$ of $(\mathrm{PEA})_{2} \mathrm{SnI}_{4}$ (red squares) and $\mathrm{CH}_{3} \mathrm{NH}_{3} \mathrm{SnI}_{3}$ (blue squares) thin films processed on $\mathrm{mp}-\mathrm{Al}_{2} \mathrm{O}_{3}$ and measured under dark and air conditions.

observation suggests that either interfacial charge carrier recombination kinetics in this system occurs on time scales faster than the instrument response of the spectrometer or the yield of charge separation is negligible. In contrast, optical excitation of the mp- $\mathrm{TiO}_{2} /(\mathrm{PEA})_{2} \mathrm{SnI}_{4}$ system is likely to result in the formation of tightly bound excitons (electron-hole pairs) in (PEA) ${ }_{2} \mathrm{SnI}_{4}$. It is highly plausible that the energy difference $(\Delta E \approx 0.3 \mathrm{eV}$, Figure $2 \mathrm{c})$ between the conduction band edges of the $\mathrm{TiO}_{2}$ and $(\mathrm{PEA})_{2} \mathrm{SnI}_{4}$ provides the necessary driving force to overcome the exciton binding energy of (PEA) $)_{2} \mathrm{SnI}_{4}\left(\sim 0.190 \mathrm{eV}^{43}\right)$ and split the electron-hole pair. The present findings clearly show that (PEA) ${ }_{2} \mathrm{SnI}_{4}$ can function as a sensitizer on $\mathrm{mp}-\mathrm{TiO}_{2}$, leading to high-yield and long-lived charge separation.

The next question that arises relates to the origin of the superior $\mathrm{PL}$ properties of (PEA) $)_{2} \mathrm{SnI}_{4}$ as compared to $\mathrm{CH}_{3} \mathrm{NH}_{3} \mathrm{SnI}_{3}$. Most probably, this behavior can be attributed to the previously mentioned self-doping of the $3 \mathrm{D}$ material, $\mathrm{CH}_{3} \mathrm{NH}_{3} \mathrm{SnI}_{3}$. The unwanted oxidation of $\mathrm{Sn}^{2+}$ to $\mathrm{Sn}^{4+}$ and the formation of $\mathrm{Sn}^{2+}$ vacancies increase the background concentration of free holes in the valence band of perovskite, which in turn could make photoexcited electrons in the conduction band recombine back to the ground state unusually fast (consistent with the short decay time constant in $\mathrm{CH}_{3} \mathrm{NH}_{3} \mathrm{SnI}_{3}$; Table S1) and nonradiatively. ${ }^{47}$ Moreover, low-dimensional perovskites show semiconducting properties $^{23,48}$ and represent a way of intrinsically avoiding unwanted metallic behavior seen in conventional 3D materials. Interestingly, we also find that the $2 \mathrm{D}(\mathrm{PEA})_{2} \mathrm{SnI}_{4}$ perovskite displays better stability than $\mathrm{CH}_{3} \mathrm{NH}_{3} \mathrm{SnI}_{3}$ when aged under ambient air in the dark, as shown in Figure 2d. Raw absorbance versus aging profiles are presented in the Supporting Information of this Letter (Figure S5). We therefore believe that an increase in the organic cation size provides a physical barrier to slow down oxygen diffusion into the perovskite film and its subsequent degradation, as observed in layered hybrid lead perovskites. ${ }^{30}$

So far, we have shown that $2 \mathrm{D}(\mathrm{PEA})_{2} \mathrm{SnI}_{4}$ displays superior light emission properties and, in particular, PL properties relative to $3 \mathrm{D} \mathrm{CH}_{3} \mathrm{NH}_{3} \mathrm{SnI}_{3}$. This observation raises an obvious question, namely, if (PEA) ${ }_{2} \mathrm{SnI}_{4}$ can be used as an emitter in visible electroluminescent devices. To investigate this, we fabricated LEDs with the following architecture, [ITO/ PEDOT:PSS $\left./(\mathrm{PEA})_{2} \mathrm{SnI}_{4} / \mathrm{F} 8 / \mathrm{LiF} / \mathrm{Al}\right]$, as illustrated in Figure 3a. PEDOT:PSS and F8 were selected as hole and electron 

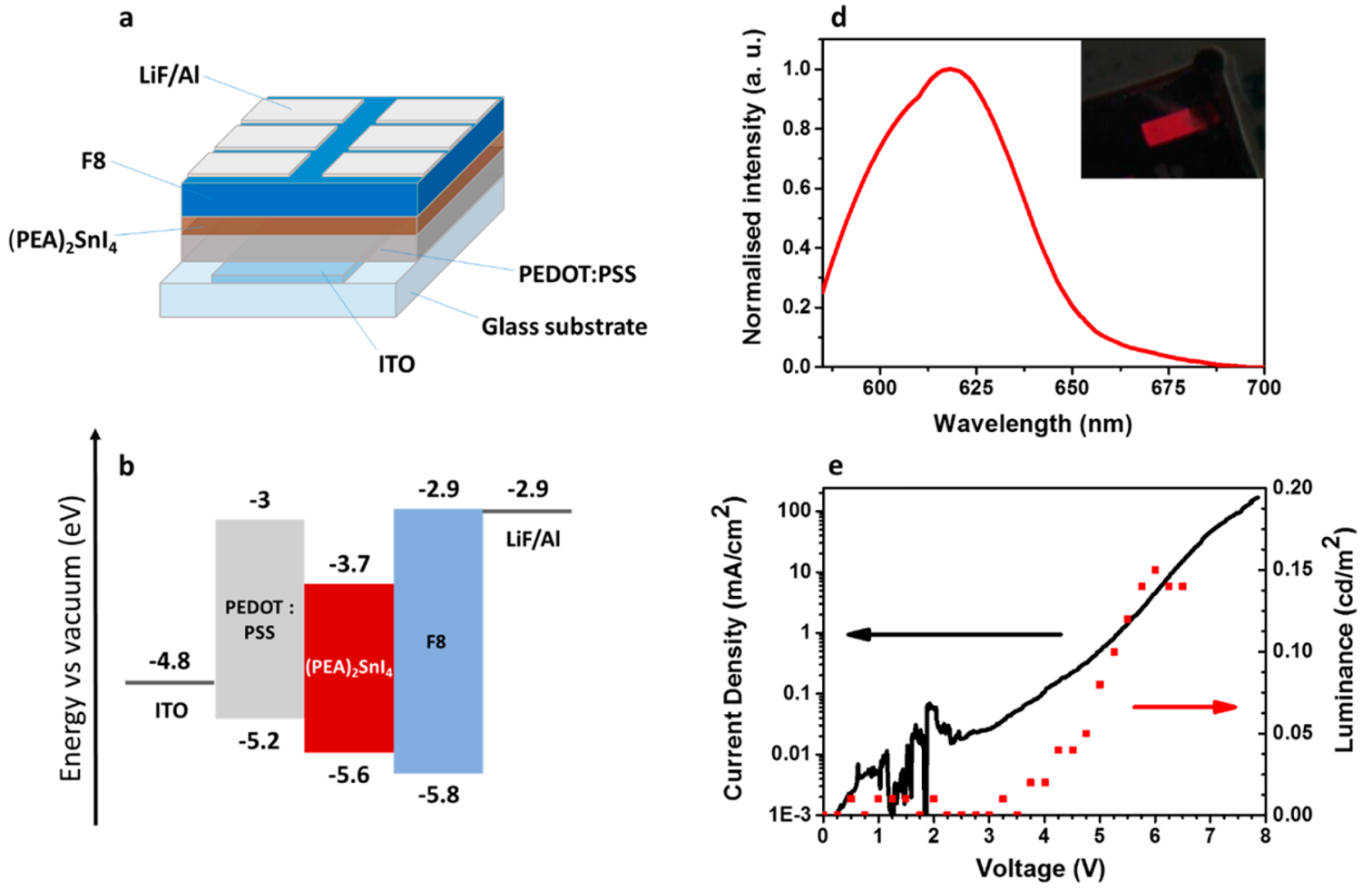

c
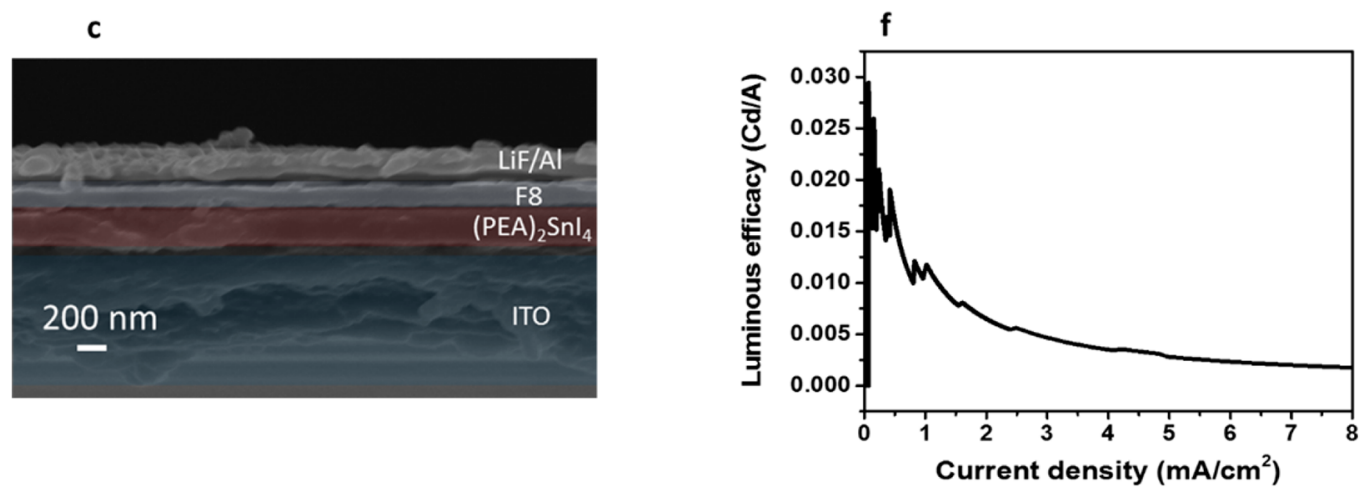

Figure 3. (a) Device structure of the (PEA) ${ }_{2} \mathrm{SnI}_{4}$ LED. (b) Energy levels vs vacuum of the different layers that define the LED. Values were obtained from literature references. ${ }^{6,26,49,50}$ (c) Cross-sectional image of the ITO/PEDOT:PSS/(PEA) ${ }_{2} \mathrm{SnI}_{4} / \mathrm{F8} / \mathrm{LiF}_{\mathrm{Al}} \mathrm{Alevice}$ (scale bar: 200 $\mathrm{nm})$. (d) Electroluminescence spectrum of a (PEA) $\mathrm{SnI}_{4}$ device, registered by applying a $4 \mathrm{~V}$ bias to the device. (Inset) Image of the LED under operation. (e) Current density-voltage (black line) and luminance-voltage (red dots) curves of the (PEA) $)_{2} \mathrm{SnI}_{4}$ device. (f) Luminous efficacy curve of the LED.

injection layers to help confine the charge carriers in (PEA) $)_{2} \mathrm{SnI}_{4}$, thus favoring exciton formation and radiative recombination (see Figure $3 b$ for the device energy diagram). In addition, the small energy difference between the contacts and their respective adjacent layers allows efficient charge carrier injection. Devices were prepared as described in the experimental section (Supporting Information). Briefly, (PEA) $)_{2} \mathrm{SnI}_{4}$ films were deposited onto PEDOT:PSS-coated ITO glass substrates by spin-coating from a DMF solution containing PEAI and $\mathrm{SnI}_{2}$ (2:1 molar ratio) followed by mild annealing at $80{ }^{\circ} \mathrm{C}$. Following deposition of F8, a $\mathrm{LiF} / \mathrm{Al}$ top contact was evaporated as a low-workfunction cathode. Crosssectional scanning electron microscopy images (Figure 3c) confirmed perovskite layer compactness and the layered structure of our device. From the data presented in Figure $3 \mathrm{c}$, device layer thicknesses were estimated to be $\sim 230 \mathrm{~nm}$ ((PEA) $\left.)_{2} \mathrm{SnI}_{4}\right), \sim 150 \mathrm{~nm}(\mathrm{~F} 8)$, and $\sim 130 \mathrm{~nm}(\mathrm{LiF} / \mathrm{Al})$.
The electroluminescence (EL) spectral characteristics of the $(\mathrm{PEA})_{2} \mathrm{SnI}_{4}$ LED are shown in Figure $3 \mathrm{~d}$ along with a photograph of a functioning device. Device characterization experiments were performed under $\mathrm{N}_{2}$ in a sealed environmental chamber. The data presented in Figure $3 \mathrm{~d}$ show that the light emitted by the (PEA) ${ }_{2} \mathrm{SnI}_{4}$ devices is red (peak: $\sim 618$ $\mathrm{nm}$ ), and it represents the first example of visible-light EL on 2D lead-free perovskite. The luminance and current density vs voltage characteristics are presented in Figure $3 \mathrm{e}$, while the luminous efficacy vs current chart can be found in Figure $3 f$. The turn-on voltage was found to be around $3.6 \mathrm{~V}$ (current efficacy: $\sim 0.029 \mathrm{~cd} / \mathrm{A}$ ), and the device appeared brighter as the voltage progressively increased. The maximum luminance achieved was $0.15 \mathrm{~cd} / \mathrm{m}^{2}$ at a $6 \mathrm{~V}$ potential difference (ITO positive with respect to $\mathrm{Al}$ ) with a current density of $4.7 \mathrm{~mA}$ / $\mathrm{cm}^{2}$, corresponding to a current efficacy of $\sim 0.003 \mathrm{Cd} / \mathrm{A}$.

The modest efficiency of our proof-of-concept (PEA) ${ }_{2} \mathrm{SnI}_{4}$ LEDs suggests that the device architecture is not optimal. More 
specifically, top-view scanning electron microscopy images (Figure S6) reveal that the topography in (PEA) ${ }_{2} \mathrm{SnI}_{4}$ consists of micron-sized, interconnected perovskite islands that might not facilitate full coverage when applying the F8 layer. Further morphology and perovskite formation optimization is expected to improve device performance. Additionally, we believe that further enhancements in performance may also be realized by tuning the orientation of the layered perovskite with respect to the substrate to facilitate electrically driven exciton generation and radiative decay. We note that the relatively broad EL spectrum seen in our LEDs may be related to perovskite morphology and/or to the presence of emissive excitons in trap states arising from crystal defects. Further, detailed studies addressing device optimization and fabrication with $\mathrm{Br}$ containing (PEA) ${ }_{2} \mathrm{SnI}_{x} \mathrm{Br}_{4-x}$ will form part of our future work and will be reported in due course.

In summary, in this Letter, we have reported the processing and characterization of (PEA) $)_{2} \mathrm{SnI}_{x} \mathrm{Br}_{4-x}$, a family of $2 \mathrm{D}$ layered perovskite materials that show tunable visible light absorption and emission properties via halide band gap engineering. More importantly, the superior light emission properties of (PEA) $)_{2} \mathrm{SnI}_{4}$ over its $3 \mathrm{D} \quad \mathrm{CH}_{3} \mathrm{NH}_{3} \mathrm{SnI}_{3}$ counterpart are demonstrated via steady-state/time-resolved PL spectroscopy as (PEA) ${ }_{2} \mathrm{SnI}_{4}$ emits more intensely upon photoexcitation, shows higher PLQE, and exhibits much slower radiative recombination kinetics than $\mathrm{CH}_{3} \mathrm{NH}_{3} \mathrm{SnI}_{3}$. We have also shown that $(\mathrm{PEA})_{2} \mathrm{SnI}_{4}$ effectively sensitizes $\mathrm{mp}-\mathrm{TiO}_{2}$. We suggest that the preferable properties of this $2 \mathrm{D}$ material arise from the semiconducting behavior that it acquires when adopting this dimensionality, ${ }^{23}$ in contrast with the p-type metallic character of $\mathrm{CH}_{3} \mathrm{NH}_{3} \mathrm{SnI}_{3}$ caused by the intrinsic presence of $\mathrm{Sn}^{4+}$ traces in its structure as a result of $\mathrm{Sn}^{2+}$ oxidation. $^{20,21}$ Additionally, we demonstrate superior air stability of $(\mathrm{PEA})_{2} \mathrm{SnI}_{4}$ versus $\mathrm{CH}_{3} \mathrm{NH}_{3} \mathrm{SnI}_{3}$. We report a first example of visible, lead-free perovskite LED based on 2D (PEA) ${ }_{2} \mathrm{SnI}_{4}$ as the emitter. This proof-of-principle demonstration of EL from low-dimensionality $\mathrm{Sn}$ (II) perovskites offers promising prospects for the development of lead-free perovskite optoelectronics.

\section{ASSOCIATED CONTENT}

\section{S Supporting Information}

The Supporting Information is available free of charge on the ACS Publications website at DOI: 10.1021/acsenergylett.7b00414.

Materials and methods, perovskite XRD patterns, absorption spectra of $2 \mathrm{D}$ and $3 \mathrm{D}$ perovskites, variation of steady-state PL peak wavelengths of (PEA) ${ }_{2} \mathrm{SnI}_{x} \mathrm{Br}_{4-x}$ vs $x$, steady-state $\mathrm{PL}$ normalization details, perovskite absorbance versus aging profiles, top-view SEM image of $(\mathrm{PEA})_{2} \mathrm{SnI}_{4}$, and fitting parameters of time-resolved $\mathrm{PL}$ decays (PDF)

\section{AUTHOR INFORMATION}

\section{Corresponding Author}

*E-mail: s.a.haque@imperial.ac.uk.

\section{ORCID $\odot$}

Saif A. Haque: 0000-0001-5483-3321

\section{Notes}

The authors declare no competing financial interest.

\section{ACKNOWLEDGMENTS}

S.A.H. acknowledges financial support from EPRSC via EP/ M023532/1, EP/K010298/1, and EP/K030671/1 grants.

\section{REFERENCES}

(1) Kojima, A.; Teshima, K.; Shirai, Y.; Miyasaka, T. Organometal Halide Perovskites as Visible-Light Sensitizers for Photovoltaic Cells. J. Am. Chem. Soc. 2009, 131, 6050-6051.

(2) Kim, H.-S.; Lee, C.-R; Im, J.-H.; Lee, K.-B.; Moehl, T.; Marchioro, A.; Moon, S.-J.; Humphry-Baker, R.; Yum, J.-H.; Moser, J. E.; et al. Lead Iodide Perovskite Sensitized All-Solid-State Submicron Thin Film Mesoscopic Solar Cell with Efficiency Exceeding 9\%. Sci. Rep. 2012, 2, 591.

(3) Lee, M. M.; Teuscher, J.; Miyasaka, T.; Murakami, T. N.; Snaith, H. J. Efficient Hybrid Solar Cells Based on Meso-Superstructured Organometal Halide Perovskites. Science 2012, 338, 643-647.

(4) Stranks, S. D.; Eperon, G. E.; Grancini, G.; Menelaou, C.; Alcocer, M. J. P.; Leijtens, T.; Herz, L. M.; Petrozza, A.; Snaith, H. J. Electron-Hole Diffusion Lengths Exceeding 1 Micrometer in an Organometal Trihalide Perovskite Absorber. Science 2013, 342, 341344.

(5) Burschka, J.; Pellet, N.; Moon, S.-J.; Humphry-Baker, R.; Gao, P.; Nazeeruddin, M. K.; Grätzel, M. Sequential Deposition as a Route to High-Performance Perovskite-Sensitized Solar Cells. Nature 2013, 499, 316-319.

(6) Tan, Z.-K.; Moghaddam, R. S.; Lai, M. L.; Docampo, P.; Higler, R.; Deschler, F.; Price, M.; Sadhanala, A.; Pazos, L. M.; Credgington, D.; et al. Bright Light-Emitting Diodes Based on Organometal Halide Perovskite. Nat. Nanotechnol. 2014, 9, 1-6.

(7) Cho, H.; Jeong, S.-H.; Park, M.-H.; Kim, Y.-H.; Wolf, C.; Lee, C.L.; Heo, J. H.; Sadhanala, A.; Myoung, N.; Yoo, S.; et al. Overcoming the Electroluminescence Efficiency Limitations of Perovskite LightEmitting Eiodes. Science 2015, 350, 1222-1225.

(8) Li, G.; Tan, Z. K.; Di, D.; Lai, M. L.; Jiang, L.; Lim, J. H. W.; Friend, R. H.; Greenham, N. C. Efficient Light-Emitting Diodes Based on Nanocrystalline Perovskite in a Dielectric Polymer Matrix. Nano Lett. 2015, 15, 2640-2644.

(9) Veldhuis, S. A.; Boix, P. P.; Yantara, N.; Li, M.; Sum, T. C.; Mathews, N.; Mhaisalkar, S. G. Perovskite Materials for Light-Emitting Diodes and Lasers. Adv. Mater. 2016, 28, 6804-6834.

(10) Stoumpos, C. C.; Malliakas, C. D.; Kanatzidis, M. G. Semiconducting Tin and Lead Iodide Perovskites with Organic Cations: Phase Transitions, High Mobilities, and Near-Infrared Photoluminescent Properties. Inorg. Chem. 2013, 52, 9019-9038.

(11) Protesescu, L.; Yakunin, S.; Bodnarchuk, M. I.; Krieg, F.; Caputo, R.; Hendon, C. H.; Yang, R. X.; Walsh, A.; Kovalenko, M. V. Nanocrystals of Cesium Lead Halide Perovskites (CsPbX3, X $=\mathrm{Cl}, \mathrm{Br}$, and I): Novel Optoelectronic Materials Showing Bright Emission with Wide Color Gamut. Nano Lett. 2015, 15, 3692-3696.

(12) Aristidou, N.; Sanchez-Molina, I.; Chotchuangchutchaval, T.; Brown, M.; Martinez, L.; Rath, T.; Haque, S. A. The Role of Oxygen in the Degradation of Methylammonium Lead Trihalide Perovskite Photoactive Layers. Angew. Chem., Int. Ed. 2015, 54, 8208-8212.

(13) Noel, N. K.; Stranks, S. D.; Abate, A.; Wehrenfennig, C.; Guarnera, S.; Haghighirad, A.; Sadhanala, A.; Eperon, G. E.; Pathak, S. K.; Johnston, M. B.; et al. Lead-Free Organic-Inorganic Tin Halide Perovskites for Photovoltaic Applications. Energy Environ. Sci. 2014, 7, 3061-3068.

(14) Hao, F.; Stoumpos, C. C.; Cao, D. H.; Chang, R. P. H.; Kanatzidis, M. G. Lead-Free Solid-State Organic-Inorganic Halide Perovskite Solar Cells. Nat. Photonics 2014, 8, 489-494.

(15) Liao, W.; Zhao, D.; Yu, Y.; Grice, C. R.; Wang, C.; Cimaroli, A. J.; Schulz, P.; Meng, W.; Zhu, K.; Xiong, R.-G.; et al. Lead-Free Inverted Planar Formamidinium Tin Triiodide Perovskite Solar Cells Achieving Power Conversion Efficiencies up to $6.22 \%$. Adv. Mater. 2016, 28, 9333-9340.

(16) Hong, W.-L.; Huang, Y.-C.; Chang, C.-Y.; Zhang, Z.-C.; Tsai, H.-R.; Chang, N.-Y.; Chao, Y.-C. Efficient Low-Temperature Solution- 
Processed Lead-Free Perovskite Infrared Light-Emitting Diodes. Adv. Mater. 2016, 28, 8029-8036.

(17) Lai, M. L.; Tay, T. Y. S.; Sadhanala, A.; Dutton, S. E.; Li, G.; Friend, R. H.; Tan, Z. K. Tunable Near-Infrared Luminescence in Tin Halide Perovskite Devices. J. Phys. Chem. Lett. 2016, 7, 2653-2658.

(18) Mitzi, D. B.; Feild, C. a.; Schlesinger, Z.; Laibowitz, R. B. Transport, Optical, and Magnetic Properties of the Conducting Halide Perovskite $\mathrm{CH}_{3} \mathrm{NH}_{3} \mathrm{SnI}_{3}$. J. Solid State Chem. 1995, 114, 159-163.

(19) Takahashi, Y.; Obara, R.; Lin, Z.-Z.; Takahashi, Y.; Naito, T.; Inabe, T.; Ishibashi, S.; Terakura, K. Charge Transport in Tin-Iodide Perovskite $\mathrm{CH}_{3} \mathrm{NH}_{3} \mathrm{SnI}_{3}$ : Origin of High Conductivity. Dalton Trans. 2011, 40, 5563-5568.

(20) Takahashi, Y.; Hasegawa, H.; Takahashi, Y.; Inabe, T. Hall Mobility in Tin Iodide Perovskite $\mathrm{CH}_{3} \mathrm{NH}_{3} \mathrm{SnI}_{3}$ : Evidence for a Doped Semiconductor. J. Solid State Chem. 2013, 205, 39-43.

(21) Kumar, M. H.; Dharani, S.; Leong, W. L.; Boix, P. P.; Prabhakar, R. R.; Baikie, T.; Shi, C.; Ding, H.; Ramesh, R.; Asta, M.; et al. LeadFree Halide Perovskite Solar Cells with High Photocurrents Realized Through Vacancy Modulation. Adv. Mater. 2014, 26, 7122-7127.

(22) Marshall, K. P.; Walker, M.; Walton, R. I.; Hatton, R. A.; Kojima, A.; Teshima, K.; Shirai, Y.; Miyasaka, T.; Xu, T.; Chen, L.; et al. Enhanced Stability and Efficiency in Hole-Transport-Layer-Free $\mathrm{CsSnI}_{3}$ perovskite photovoltaics. Nat. Energy 2016, 1, 16178.

(23) Mitzi, D. B.; Feild, C. A.; Harrison, W. T. A.; Guloy, A. M. Conducting Tin Halides with a Layered Organic-Based Perovskite Structure. Nature 1994, 369, 467-469.

(24) Kagan, C. R.; Mitzi, D. B.; Dimitrakopoulos, C. D. OrganicInorganic Hybrid Materials as Semiconducting Channels in Thin-Film Field-Effect Transistors. Science 1999, 286, 945-947.

(25) Mitzi, D. B.; Dimitrakopoulos, C. D.; Rosner, J.; Medeiros, D. R.; Xu, Z.; Noyan, C. Hybrid Field-Effect Transistor Based on a LowTemperature Melt-Processed Channel Layer. Adv. Mater. 2002, 14, $1772-1776$.

(26) Matsushima, T.; Hwang, S.; Sandanayaka, A. S. D.; Qin, C.; Terakawa, S.; Fujihara, T.; Yahiro, M.; Adachi, C. Solution-Processed Organic-Inorganic Perovskite Field-Effect Transistors with High Hole Mobilities. Adv. Mater. 2016, 28, 10275-10281.

(27) Quan, L. N.; Yuan, M.; Comin, R.; Voznyy, O.; Beauregard, E. M.; Hoogland, S.; Buin, A.; Kirmani, A. R.; Zhao, K.; Amassian, A.; et al. Ligand-Stabilized Reduced-Dimensionality Perovskites. J. Am. Chem. Soc. 2016, 138, 2649-2655.

(28) Cheng, Z.; Lin, J. Layered Organic-Inorganic Hybrid Perovskites: Structure, Optical Properties, Film Preparation, Patterning and Templating Engineering. CrystEngComm 2010, 12, 2646.

(29) Zhang, Y.; Liu, J.; Wang, Z.; Xue, Y.; Ou, Q.; Polavarapu, L.; Zheng, J.; Qi, X.; Bao, Q. Synthesis, Properties, and Optical Applications of Low-Dimensional Perovskites. Chem. Commun. 2016, 52, 13637-13655.

(30) Smith, I. C.; Hoke, E. T.; Solis-Ibarra, D.; McGehee, M. D.; Karunadasa, H. I. A Layered Hybrid Perovskite Solar-Cell Absorber with Enhanced Moisture Stability. Angew. Chem. 2014, 126, 1141411417.

(31) Cao, D. H.; Stoumpos, C. C.; Farha, O. K.; Hupp, J. T.; Kanatzidis, M. G. 2D Homologous Perovskites as Light-Absorbing Materials for Solar Cell Applications. J. Am. Chem. Soc. 2015, 137, 7843-7850.

(32) Tsai, H.; Nie, W.; Blancon, J.-C.; Stoumpos, C. C.; Asadpour, R.; Harutyunyan, B.; Neukirch, A. J.; Verduzco, R.; Crochet, J. J.; Tretiak, S.; et al. High-Efficiency Two-Dimensional RuddlesdenPopper Perovskite Solar Cells. Nature 2016, 536, 312-316.

(33) Era, M.; Morimoto, S.; Tsutsui, T.; Saito, S. Organic-Inorganic Heterostructure Electroluminescent Device Using a Layered Perovskite Semiconductor $\left(\mathrm{C}_{6} \mathrm{H}_{5} \mathrm{C}_{2} \mathrm{H}_{4} \mathrm{NH}_{3}\right)_{2} \mathrm{PbI}_{4}$. Appl. Phys. Lett. 1994, 65, $676-678$.

(34) Hattori, T.; Taira, T.; Era, M.; Tsutsui, T.; Saito, S. Highly Efficient Electroluminescence from a Heterostructure Device Combined with Emissive Layered Perovskite and an ElectronTransporting Organic Compound. Chem. Phys. Lett. 1996, 254, 103-108.
(35) Chondroudis, K.; Mitzi, D. B. Electroluminescence from an Organic-Inorganic Perovskite Incorporating a Quaterthiophene Dye within Lead Halide Perovskite Layers. Chem. Mater. 1999, 11, 30283030.

(36) Byun, J.; Cho, H.; Wolf, C.; Jang, M.; Sadhanala, A.; Friend, R. H.; Yang, H.; Lee, T. Efficient Visible Quasi-2D Perovskite LightEmitting Diodes. Adv. Mater. 2016, 28, 7515-7520.

(37) Liang, D.; Peng, Y.; Fu, Y.; Shearer, M. J.; Zhang, J.; Zhai, J.; Zhang, Y.; Hamers, R. J.; Andrew, T. L.; Jin, S. Color-Pure Violet Light-Emitting Diodes Based on Layered Lead Halide Perovskite Nanoplates. ACS Nano 2016, 10, 6897-6904.

(38) Pan, J.; Quan, L. N.; Zhao, Y.; Peng, W.; Murali, B.; Sarmah, S. P.; Yuan, M.; Sinatra, L.; Alyami, N.; Liu, J.; et al. Highly Efficient Perovskite Quantum Dot Light-Emitting Diodes by Surface Engineering. Adv. Mater. 2016, 28, 8718-8725.

(39) Yuan, M.; Quan, L. N.; Comin, R; Walters, G.; Sabatini, R.; Voznyy, O.; Hoogland, S.; Zhao, Y.; Beauregard, E. M.; Kanjanaboos, P.; et al. Perovskite Energy Funnels for Efficient Light-Emitting Diodes. Nat. Nanotechnol. 2016, 11, 872-877.

(40) Kim, Y.-H.; Cho, H.; Lee, T.-W. Metal Halide Perovskite Light Emitters. Proc. Natl. Acad. Sci. U. S. A. 2016, 113, 11694-11702.

(41) Ishihara, T.; Takahashi, J.; Goto, T. Optical Properties Due to Electronic Transitions in Two-Dimensional Semiconductors $\left(\mathrm{C}_{\mathrm{n}} \mathrm{H}_{2 \mathrm{n}+1} \mathrm{NH}_{3}\right)_{2} \mathrm{PbI}_{4}$. Phys. Rev. B: Condens. Matter Mater. Phys. 1990, 42, 11099-11107.

(42) Ishihara, T. Optical Properties of PbI-Based Perovskite Structures. J. Lumin. 1994, 60-61 (C), 269-274.

(43) Papavassiliou, G. C.; Koutselas, I. B.; Terzis, a.; Whangbo, M.-H. Structural and Electronic Properties of the Natural Quantum-Well System $\left(\mathrm{C}_{6} \mathrm{H}_{5} \mathrm{CH}_{2} \mathrm{CH}_{2} \mathrm{NH}_{3}\right)_{2} \mathrm{SnI}_{4}$. Solid State Commun. 1994, 91, 695-698.

(44) Sichert, J. A.; Tong, Y.; Mutz, N.; Vollmer, M.; Fischer, S.; Milowska, K. Z.; Garcia Cortadella, R.; Nickel, B.; Cardenas-Daw, C.; Stolarczyk, J. K.; et al. Quantum Size Effect in Organometal Halide Perovskite Nanoplatelets. Nano Lett. 2015, 15, 6521-6527.

(45) Boix, P. P.; Nonomura, K.; Mathews, N.; Mhaisalkar, S. G. Current Progress and Future Perspectives for Organic/Inorganic Perovskite Solar Cells. Mater. Today 2014, 17, 16-23.

(46) Odier, P.; Rifflet, J. C.; Loup, J. P. Electron Emission Measurements and the Defect Structure of $\alpha-\mathrm{Al}_{2} \mathrm{O}_{3}$. J. Mater. Sci. 1984, 19, 2121-2135.

(47) Parrott, E. S.; Milot, R. L.; Stergiopoulos, T.; Snaith, H. J.; Johnston, M. B.; Herz, L. M. E ffect of Structural Phase Transition on Charge-Carrier Lifetimes and Defects in $\mathrm{CH}_{3} \mathrm{NH}_{3} \mathrm{SnI}_{3}$ Perovskite. J. Phys. Chem. Lett. 2016, 7, 1321-1326.

(48) Liu, X.; Chen, S.; Hauser, J.; Laukhin, V.; Decurtins, S.; Aschauer, U.; Liu, S. X. Low-Dimensional Tin(II) Iodide Perovskite Structures Templated by an Aromatic Heterocyclic Cation. Cryst. Growth Des. 2016, 16, 5230-5237.

(49) Sutherland, B. R; Sargent, E. H. Perovskite Photonic Sources. Nat. Photonics 2016, 10, 295-302.

(50) Liu, J.; Zhang, H.; Dong, H.; Meng, L.; Jiang, L.; Jiang, L.; Wang, Y.; Yu, J.; Sun, Y.; Hu, W.; et al. High Mobility Emissive Organic Semiconductor. Nat. Commun. 2015, 6, 10032-10039. 